Cadernos de História, Belo Horizonte, v. 22, n. 36, Junho de 2021

DOI: https://doi.org/10.5752/P.2237-8871.2021v22n36p24-43

\section{José MARIA AlKMIN: PENSAMENTO ECONÔMICO, ARTICULAÇÕES POLÍTICAS E ATUAÇÃO NO MiNisTÉRIO DA \\ FAZENDA}

Armando Dalla Costa

Universidade Federal do Paraná ajdcosta@uol.com.br

Ivan Colangelo SALOMÃo

Universidade Federal do Paraná

ivansalomao@gmail.com

\title{
RESUMO
}

José Maria Alkmin foi um dos mais importantes políticos mineiros do século XX. Conquanto não tenha sido eleito governador de seu estado, Alkmin exerceu papel relevante na política mineira por mais de duas décadas. Além da atividade política, teve um papel relevante na história intelectual de Belo Horizonte ao fundar a Faculdade de Filosofia da Universidade de Minas Gerais. Próximo a Benedito Valadares e, sobretudo, Juscelino Kubistchek, o advogado, deputado e ministro da Fazenda colaborou na condução da economia brasileira no final dos anos 1950, oportunidade que lhe permitiu operacionalizar suas ideias econômicas, objeto de estudo deste artigo. Ainda que por demais esquemático, pode-se caracterizar o pensamento econômico de José Maria Alkmin como liberal e conservador, hipótese corroborada tanto pela sua atuação nos postos de execução de política pública como pelas causas políticas às quais se dedicou. Ainda assim, restou afamado mais pela atuação na Câmara dos Deputados como por um formulador de políticas econômicas.

Palavras-chave: José Maria Alkmin; Pensamento econômico; Ministério da Fazenda

Recebido em 03 de março de 2020.

Aprovado em 08 de junho de 2020. 
Cadernos de História, Belo Horizonte, v. 22, n. 36, Junho de 2021

DOI: https://doi.org/10.5752/P.2237-8871.2021v22n36p24-43

\author{
José Maria AlKmin: \\ ECONOMIC THOUGHT, \\ POLITICAL ARTICULATIONS AND \\ PERFORMANCE IN THE MINISTRY \\ OF FINANCE
}

Armando Dalla Costa

Universidade Federal do Paraná

ajdcosta@uol.com.br

Ivan Colangelo SAlOMÃo

Universidade Federal do Paraná

ivansalomao@gmail.com

\begin{abstract}
José Maria Alkmin was one of the most important Minas Gerais politicians of the 20th century. Although he was not elected governor of his state, Alkmin exercised an important role in Minas Gerais politics for more than two decades. Beyond his political activity, he played an important role in the intellectual history of Belo Horizonte when he founded the Faculty of Philosophy at the University of Minas Gerais. Close to Benedito Valadares and Juscelino Kubistchek, the lawyer, deputy and Minister of Finance supported the administration of Brazilian economy in the late 1950s, an opportunity that allowed him to operationalize his economic ideas, the main object of this article. Even so, José Maria Alkmin can be characterized, in economic issues, as liberal and conservative, a hypothesis corroborated both by his performance in public posts and by the political causes to which he dedicated himself. Even so, he remained more famous for his work in the Chamber of Deputies as a formulator of economic policies.
\end{abstract}

Keywords: José Maria Alkmin; Economic Thought; Ministry of Finance 


\section{INTRODUÇÃo}

Alkmin alcançou apenas 4,7\% dos votos nas eleições presidenciais de 2018. No entanto, não é de Geraldo Alckmin, mas de seu tio-avô, José Maria Alkmin o conteúdo deste artigo. José Maria exerceu longa carreira política, chegando a ser vice-presidente do Brasil entre 15 de abril de 1964 e 15 de março de 1967, no governo do marechal Castelo Branco (Badaró, 1996).

Nos termos de Oliveira (2018), é correto afirmar que os Alkmin formam uma "família genealógica no poder". Para Badaró (1996, p. 132), a ascendência familiar de Alkmin tinha fortes componentes de natureza política, tanto do lado paterno quanto do materno. Condizente com a reconhecida atuação na região em período remoto, o ouvidor Gonçalo Alkmin demonstrou, em todas as suas ações, uma notável intuição política. Pelo lado de sua mãe, Sérgia, toda a linhagem familiar dos Caldeira Brant indicava forte tendência para a ação política e a vida pública, como indicavam os atos do contratador Felisberto Caldeira Brant, conseguindo, em pouco tempo, organizar a mineração de diamante e levar a paz entre os garimpeiros. A candidatura à Presidência da República de outro membro da família, em 2018, demonstra que a genealogia Alkmin não se alijou completamente do poder no Brasil contemporâneo (Oliveira, 2001).

José Maria nasceu na cidade mineira de Bocaiúva, no dia 11 de junho de 1901, filho de Herculano Augusto de Alkmin e Sérgia Caldeira de Alkmin. Assim como o Brasil, a Minas Gerais do início do século XX era um estado essencialmente agrário, onde seu pai ganhava a vida como "negociador de gados" no tempo em que muitas tropas circulavam pelo interior do estado (Badaró, 1996, p. 37). Sua educação ficou por conta da mãe, que permanecia em casa cuidando dos onze filhos do casal. Para completar a renda da família, Sérgia se dedicava a fazer doces caseiros, que Alkmin vendia nas vizinhanças ao voltar da escola.

Por vezes, saía com o pai levando gado pelo interior, onde teve contato com a realidade rural e as pequenas cidades, conhecimento que lhe seria útil como base eleitoral na futura carreira política. Entre uma viagem e outra, contraiu malária, da qual curou-se com dificuldades. Sua mãe, temendo novo surto da doença, o enviou para uma cidade maior, Diamantina, em 1914, onde foi morar na casa de Chico Alkmin, irmão por parte do primeiro casamento do pai.

Lá, conheceu pessoas e fez contatos que lhe foram fundamentais na futura vida política. Logo ao chegar, matriculou-se na Escola Normal Américo Lopes, onde conheceu Maria Dasdores Fonseca Alkmin, nascida Maria Dasdores Kubitschek da Fonseca, prima de Juscelino Kubitscheck (JK), seminarista naquele ano de 1914 (Badaró, 1996, p. 58). Dasdores, como era conhecida e chamada após o casamento, tornou-se sua esposa, enquanto Juscelino foi amigo da vida toda e companheiro de atividades no campo da política. Em diversas ocasiões, estiveram juntos, um apoiando o outro, assim como discordaram em outros momentos.

Seus horizontes se ampliaram quando passou num concurso para telegrafista, em 1921. Diferentemente de Juscelino, que também foi aprovado e designado para Belo Horizonte, Alkmin foi enviado para Porto Alegre. A passagem por Diamantina tornou-se muito útil a Alkmin por diversas razões. Além de melhorar seu nível intelectual, tanto pela escola e "lendo tudo que lhe caía nas mãos", também adquiriu confiança em si próprio e aperfeiçoou a arte de 
conversar e fazer amigos com dos quais se manteve próximo por muitos anos.

Os contatos profissionais se ampliaram pelos novos trabalhos em que Alkmin se envolveu. Enquanto ainda servia em Porto Alegre, seu nome foi sorteado para prestar serviço militar no $12^{\circ}$ Regimento de Infantaria de Belo Horizonte. Além de voltar ao estado natal, incorporou-se às fileiras do Exército sob o comando do tenente Humberto de Alencar Castelo Branco. Por suas próprias virtudes, logo foi promovido a cabo, nem de longe imaginando que, ao lado deste tenente, se tornariam, respectivamente, presidente e vice-presidente da República.

Diferentemente dos dias atuais, no Brasil da década de 1920 as opções de ensino superior eram muito mais limitadas. Boa parte da intelectualidade do país bacharelava-se em Direito. Foi o que fez Alkmin, iniciando a Faculdade de Direito em 1925 e formando-se no dia 25 de dezembro de 1929. Como faria em muitas outras ocasiões futuras, pronunciou o discurso de formatura de sua turma. Uma vez formado, casou-se com Dasdores em 8 de fevereiro de 1930, com a qual teve três filhos: José Maria Alkmin Filho, Luciano Alkmin e Leonardo Alkmin.

Antes de iniciar sua carreira política, Alkmin envolveu-se em diversas outras atividades. Em 1925, ingressou na Imprensa Oficial do Estado, como repórter do Minas Gerais, onde chegou ao posto de diretor, cargo que ocupou até 1932. Antes, em 1931, fora designado por Olegário Maciel, interventor de Minas, para ser o reitor do Ginásio Mineiro, o mais importante estabelecimento de ensino da capital. Em 1932, foi escolhido como fiscal do Banco Hipotecário e Agrícola de Minas Gerais, estabelecimento oficial de crédito do estado. No mesmo ano, começou a trabalhar no escritório de advocacia de Abílio Machado, onde conheceu entre outros, Pedro Aleixo e Milton Campos.

Foi trabalhando neste escritório que Alkmin estreou sua carreira jurídica. No início de 1933, Pedro Aleixo, um dos maiores criminalistas mineiros, deveria ir a Ouro Preto para a defesa de Anastásio Bini, italiano dono de fábrica de móveis que assassinou Aurélio Augusto de Almeida, rico comerciante que emprestava dinheiro a juros, o típico agiota. Aconteceu que Pedro Aleixo não pôde ir ao julgamento, sugerindo que Alkmin o substituísse. No dia do julgamento, confrontaram-se ele e um recém-formado advogado, Tancredo de Almeida Neves, que atuou como representante do Ministério Público. Feita a acusação, Alkmin passou à defesa e o júri absolveu o réu. Desde então, por diversas ocasiões, Alkmin e Tancredo se enfrentaram na arena política.

Foi neste momento de sua carreira profissional que Alkmin resolveu entrar para a política, atividade que não abandonou até o final da vida. Foi incluído pelo presidente de Minas Gerais, Olegário Maciel, na chapa do Partido Progressista Mineiro como candidato às eleições da Assembleia Nacional Constituinte. Em 3 de maio de 1933 ocorreu a eleição, e no dia 22 de julho a comissão encarregada de proceder as apurações encerrou seus trabalhos. Pela chapa do Partido Progressista foram eleitos 31 deputados, sendo seis pelo Partido Republicano Mineiro. Assim, Alkmin inaugurava sua carreira política em nível nacional.

Juscelino Kubitschek e José Maria Alkmin candidataram-se à Câmara Federal Ordinária 90 dias após promulgada a Constituição de 1934. Ambos se elegeram, porém Alkmin foi convidado para assumir o cargo do recém-criado Tribunal de Contas do Estado de Minas. Renunciou a seu mandato e aceitou o convite. Continuando seus trabalhos em diversas 
atividades político-econômicas, Alkmin foi nomeado, em setembro de 1936, para a Secretaria do Interior de Minas Gerais. Suas duas principais políticas no cargo foram a assistência aos menores e os já citados trabalhos com o setor penitenciário do Estado. Em suas palavras, "há consenso entre a população que os presos da penitenciária estadual de Ouro Preto eram sentenciados à morte. Jamais voltavam. Era imperativo, portanto, dar aos presídios do estado uma orientação mais humana"1. Trata-se, em sua própria visão, de um de seus mais relevantes legados administrativos.

Em 18 de julho de 1938, foi inaugurado o novo prédio da Penitenciária de Neves. O governador, Benedito Valadares, no ato de inauguração, nomeou Alkmin para a direção do estabelecimento, destituindo-o do cargo de Secretário do Interior. José Maria assumiu o novo cargo com a intenção de colocar em prática outra mentalidade na administração penitenciária estadual. Como consequência, os produtos da indústria movimentada pelos detentos, assim como os frutos da agricultura por eles explorada, eram comercializados com publicidade, a fim de permitir uma campanha positiva em favor do novo modelo. "A penitenciária Agrícola de Neves era um grande êxito para o governo e um triunfo pessoal de seu diretor” (Badaró, 1996, p. 124). Como aproximadamente $80 \%$ dos presidiários eram da zona rural, Alkmin entendia ser mais adequada a manutenção de tais abrigados próximos das respectivas regiões de origem, propondo, para tanto, a construção de prisões agrícolas em pequenas unidades regionais. Suas ideias incluíam prisão sem guardas armados e com dois terços dos condenados fora das grades para a realização de trabalhos industriais e agrícolas.

Outra atividade na qual Alkmin se envolveu, junto com um grupo de intelectuais mineiros que militava na vida cultural e política da cidade, foi na fundação, em 21 de abril de 1939, da Faculdade de Filosofia da Universidade de Minas Gerais ${ }^{2}$. Nesta, Alkmin assumiu a cátedra de Economia Política e História das Doutrinas Econômicas. Como costumava acontecer no antigo modelo de cursos, intelectuais da Filosofia e do Direito envolviam-se em disciplinas de história e de economia, como foi o caso de Alkmin.

No plano Nacional, vivia-se uma realidade politicamente conturbada, tal qual se observava em determinados países europeus. Em novembro de 1937, Vargas decretou o Estado Novo num golpe apoiado pelas Forças Armadas. As eleições e os partidos políticos foram extintos e o poder legislativo fechado em todos os níveis, centralizando o poder cada vez mais no governo federal. A justificativa oficial para o golpe foi a dificuldade de consolidar o projeto do governo dentro dos marcos democráticos, visto o cenário de polarização política entre integralistas e comunistas, além da ameaça externa de guerra mundial.

Durante os anos do Estado Novo, o desenvolvimento nacional vem a ser a prioridade do grupo dominante, o qual intensifica a intervenção do Estado nas mais diversas questões e acastela o ideal do planejamento econômico. Para Fonseca (1987), apesar da ausência de planejamento efetivo, o governo apresentou relativa coerência entre suas propostas e suas

1 Discurso de posse de Alkmin na Secretaria do Interior do Estado de Minas Gerais. Belo Horizonte, 19 de setembro de 1936.

2 Alkmin acabou por se envolver em diferentes setores da vida política, econômica, cultural e literária da sociedade. Em Belo Horizonte, além das várias atuações acima mencionadas, contribuiu na fundação de três jornais: Momento Mercantil, em 1927; a revista mensal Cidade Verde, em 1929, em parceria com Guimarães Menegale, Cyro dos Anjos, Newton Prates, Hermenegildo Chaves e; a Tribuna, onde escreviam Menegale, Alkmin, Carlos Drummond e outros intelectuais da época (Badaró, 1996, p. 150). 
ações na área econômica "como se houvesse um projeto explícito e delineado em suas linhas básicas" (FONSECA, 1987, grifos do autor). O objetivo central do desenvolvimento só ocorreria com enraizamento da intervenção estatal sob a égide da meritocracia e de normas técnicas e científicas, livres de critérios políticos e regionais, o que acabou criando as condições para a emergência de uma "tecnoestrutura estatal” (SZMRECSÁNYI, 1986). Diante a aproximação da guerra, também, fortalecia-se o discurso de defesa da industrialização, em especial a produção de ferro e aço, e da nacionalização das riquezas minerais.

A busca pela modernização do país através da indústria e da diversificação agrícola representou a deserção de dogmas ortodoxos expressos no equilíbrio orçamentário e no saneamento do meio circulante, abandonados em prol da política desenvolvimentista. Há então a ampliação da intervenção do Estado por meio da criação de órgãos, conselhos e institutos. Destacam-se em 1938 o Conselho Nacional do Petróleo, do Código de Minas e Código de Águas, centrados na regulamentação do direito a propriedade, do Instituto Brasileiro de Geografia e Estatística - IBGE, e do Departamento Administrativo do Serviço Público - DASP. Para Draibe (1985), o DASP e os "daspinhos" (órgãos criados nos estados para executar as mesmas funções) deram a forma prática do discurso do Estado Novo de substituir a política pela administração, ao basear as indicações em critérios de mérito e competência. Ainda para a autora, é nesses aparelhos estatais cada vez mais complexos, que surgiu um novo segmento social (a burocracia), e passou-se a gestar as políticas nacionais (FONSECA, 2003). Esta nova classe não era homogênea e se distinguia frente a importantes questões como o papel do estado, do capital estrangeiro e a questão social.

A legislação trabalhista também cumpriu importante papel na consolidação do capitalismo brasileiro. As leis sistematizadas na CLT atenderam diversas reivindicações históricas do operariado (como o salário mínimo, a jornada de trabalho de oito horas, as férias remuneradas e a carteira de trabalho), ao mesmo tempo, porém, atrelava os sindicatos e as organizações operárias ao domínio do Estado. A CLT também buscou preservar certo poder aquisitivo da classe trabalhadora, no sentido de consolidar o mercado para os produtos nacionais (SZMRECSÁNYI, 1986). Nota-se que a legislação amparava apenas os trabalhadores urbanos, excluindo o setor rural, explicitando a aliança do governo com os setores agrários.

Enquanto isso, em Minas Gerais, o médico (e tenente-coronel) da Polícia Militar Juscelino Kubitschek de Oliveira foi nomeado, em 1940, prefeito da cidade de Belao Horizonte. "O destino mudaria completamente o rumo de sua vida e da vida de seu inseparável amigo e companheiro de meninice, José Maria Alkmin” (Badaró, 1996, p. 125). Juscelino tomou posse na prefeitura de Belo Horizonte em 16 de abril daquele ano. Mesmo prefeito, permaneceu na chefia do Serviço de Cirurgia do Hospital Militar, onde continuou a operar todas as manhãs e assumiu, ainda, a chefia do Serviço de Urologia da Santa Casa de Misericórdia. Só abandonaria o exercício da medicina no início de 1945, quando passou a se dedicar exclusivamente à vida política.

Benedito Valadares, então governador de Minas Gerais, articulava a estratégia eleitoral da bancada mineira na eventual derrocada da ditadura do Estado Novo. Além de nomear Juscelino na prefeitura de Belo Horizonte, entendeu que estava terminada a missão de Alkmin como diretor da Penitenciária Neves. Chamou-o ao Palácio, combinando sua designação para a diretoria jurídica do Banco de Crédito Real. "Queria tê-lo bem próximo para as complicadas 
e difíceis articulações políticas exigidas pelos novos tempos” (Badaró, 1996, p. 127).

Com a intuição que caracterizava a elite política mineira, Alkmin nem sempre se comprometia diretamente nos acontecimentos. Um exemplo disso foi o fato de, no dia 24 de outubro de 1943, ter sido publicado o "Manifesto dos Mineiros", contrário à continuação da ditadura Vargas, sem a sua assinatura. Várias personalidades políticas mineiras foram perseguidas e perderam seus postos de trabalho pela subscrição ao Manifesto. Alkmin, apesar de não ter assinado o documento, pediu exoneração a Benedito Valadares de seu cargo de diretor do Banco de Crédito Real e assumiu, raramente em sua carreira, um cargo de direção em empresa privada, como superintendente das Granjas Reunidas, do grupo Matarazzo, no município de Bocaiúva. Permaneceu na função até ser chamado por Valadares e Kubitschek para as articulações que levaram à fundação do Partido Social Democrático (PSD).

No dia 8 de abril de 1945, Benedito Valadares reuniu 312 prefeitos mineiros para organizar o PSD, com a intenção de lançar o ministro e general Eurico Gaspar Dutra à Presidência da República. A primeira Comissão Executiva foi formada pelo próprio Valadares, na presidência, Israel Pinheiro na vice, Juscelino Kubitscheck como primeiro secretário, Cristiano Machado na segunda secretaria e João Beraldo como tesoureiro. Coube a Alkmin o trabalho de articulação para viabilizar a fundação do partido. Alkmin (1945), em discurso de lançamento da campanha ${ }^{3}$, afirmou: "Haveremos de nos transformar, com o tempo, no mais importante fator de equilíbrio social do Brasil, permitindo a ascensão das grandes massas sem aventuras autoritárias e dentro dos mais levantados padrões de justiça. O PSD será, pelo tempo afora, sinônimo de desenvolvimento com democracia e justiça social”.

Após a sucumbência do Estado Novo, Alkmin candidatou-se nas primeiras eleições gerais após o longo período de ditadura varguista para o parlamento federal, tomando posse na Assembleia Nacional Constituinte em janeiro de 1946. Em comparação com a experiência parlamentar anterior, os tempos haviam, obviamente, mudado. Segundo Badaró (1996, p. 173), "os trabalhadores urbanos surgiram na cena política, o país se industrializava e urbanizava, as esquerdas estavam mais fortes, com a presença de Luís Carlos Prestes e, ainda, a Assembleia contava com a presença de Getúlio Vargas”. Naquele tempo, a legislação permitia que um candidato se apresentasse para diferentes cargos em vários estados. Getúlio Vargas elegeuse senador pelos Estados do Rio Grande do Sul, São Paulo, Distrito Federal, Rio de Janeiro, Minas Gerais, Paraná e Bahia. Mais: PSD e PTB fizeram maioria na Constituinte (Couto, 2017, p. 266).

A vida política de Alkmin sempre oscilou entre sua atuação nacional e em seu estado natal. No dia 31 de janeiro de 1951, Juscelino Kubitschek tomou posse como governador de Minas Gerais e Getúlio Vargas como presidente eleito do país. Juscelino nomeou Alkmin como Secretário das Finanças, cargo do qual tomou posse no dia 1 de fevereiro voltando, assim, a atuar em seu estado de origem.

Entre idas e vindas do Rio de Janeiro para Belo Horizonte, Alkmin exerceu sua carreira política, intermediada pelo exercício de funções executivas em diversos postos de comando. Ao deixar a secretaria das finanças, assumiu no Rio de Janeiro, em 20 de outubro de 1953, a Carteira de Redescontos e Caixa de Mobilização Bancária, do Banco do Brasil, a

3 Discurso proferido por Alkmin no lançamento da campanha de Eurico Gaspar Dutra à Presidência da República. Belo Horizonte, 8 de abril de 1945. 
mais importante diretoria do estabelecimento. Ao deixar este cargo, a convite de Juscelino Kubitschek, Alkmin voltou à Câmara dos Deputados para articular a candidatura de JK à Presidência da República, abrindo mão, por sua vez, de se candidatar ao governo de Minas Gerais, sonho acalentado desde o início de sua trajetória política. JK prometeu seu apoio para o cargo nas próximas eleições de 1960.

Alkmin, nos longos debates travados na Câmara dos Deputados, contribuiu tanto para a eleição como para aperfeiçoar os detalhes que possibilitaram a posse de JK na Presidência da República. A instabilidade política da nova democracia surgida no final da Era Vargas fez com que "de agosto de 1954 a 31 de janeiro de 1956, o país tivesse cinco presidentes da República: Getúlio Vargas, Café Filho, Carlos Luz, Nereu Ramos e Juscelino Kubitscheck” (Couto, 2001, p. 339). Após longas negociações e acertos políticos, inclusive com os militares, no dia 31 de janeiro de 1956 Juscelino tomou posse como presidente eleito; em $1^{\circ}$ de fevereiro, José Maria Alkmin, assumiu o Ministério da Fazenda.

Permaneceu no cargo até dia 26 de junho de 1958 quando voltou para a Câmara dos Deputados. Um dos motivos de sua exoneração foi a disputa pelo governo de Minas Gerais nas eleições de 1960. Alkmin tinha a promessa do apoio de JK, mas Tancredo Neves também pleiteava o cargo e, o fato de Alkmin deixar o ministério beneficiaria seu concorrente. A demissão de Alkmin do Ministério da Fazenda coincidiu com a nomeação de Tancredo Neves para a Secretaria das Finanças do governo Bias Fortes, em Minas Gerais. Ao final, Alkmin não foi candidato em 1960 e Tancredo tampouco se elegeu.

Em 1962, Alkmin elegeu-se novamente para a Câmara dos Deputados, continuando, assim, seu longo mandato no legislativo. Mesmo em Brasília, sua atuação era sempre próxima aos acontecimentos de seu estado de origem. Além de sua atividade parlamentar, Alkmin era um exímio articulador político e participava diretamente nas grandes decisões políticas de Minas e de Brasília. No início de 1964, José de Magalhães Pinto, governador de Minas Gerais, convocou Alkmin, José Monteiro de Castro, seu Secretário de Segurança, e Osvaldo Pierucetti, futuro prefeito de Belo Horizonte para articular a ala civil do movimento golpista. "Deste encontro surgiram as primeiras palavras de ordem para a organização das estratégias destinadas à organização do levante militar para a derrubada de Jango, em face do perigo da dominação esquerdista” (Badaró, 1996, p. 325).

Como consequência dessas articulações e, em conjunto com outros fatores da conjuntura político-econômica da época, no dia 31 de março de 1964, somadas a contingentes do Exército, partiram as tropas mineiras em direção ao Rio; de Juiz de Fora, o general Mourão Filho iniciava sua marcha para a antiga capital da República. Em poucas horas, dissolveuse a "República sindicalista" de João Goulart e boa parte de seus companheiros de governo partiram para o exílio. Começava a perseguição a políticos alinhados ao governo deposto, enquanto Mazilli assumia a Presidência da República de maneira temporária.

Uma vez consolidado o golpe, iniciaram as tratativas para encontrar um presidente e um vice. Foi acertada uma reunião dos pessedistas com Castelo Branco. O encontro aconteceu na casa do deputado Joaquim Ramos, no qual estiveram presentes Amaral Peixoto, Martins Rodrigues, José Maria Alkmin e o anfitrião. JK chegou mais tarde à reunião e apoiou o nome de Castelo Branco à presidência. Na mesma reunião, ficou decidido que Alkmin assumiria o cargo de vice. No dia 11 de abril de 1964, depois de promulgado o Ato Institucional n. 1, de 
cuja redação participaram Alkmin, Pedro Aleixo, Luís Viana, Bilac Pinto, Carlos Medeiros e Francisco Campos, realizou-se a eleição indireta de Castelo Branco para presidente e de José Maria Alkmin para vice-presidente. Ambos tomaram posse perante o Congresso Nacional no dia 15 de abril de 1964.

Neste que foi seu cargo político mais importante, Alkmin permaneceu até o dia 14 de março de 1967, quando Castelo Branco reuniu o ministério pela última vez. Alkmin esteve presente, ao lado do governador Israel Pinheiro. No dia seguinte tomaram posse o general Costa e Silva, como presidente, e o mineiro Pedro Aleixo no cargo de vice.

Alkmin continuou, no entanto, sua carreira política. Dispensado da formalidade de afastamento da vice-presidência para se candidatar, fez parte da chapa da Arena para as eleições parlamentares de 1966, elegendo-se pela oitava vez deputado federal. Tomou posse no dia 16 de março de 1967, um dia após terminar seu mandato como vice-presidente. Em seguida, Israel Pinheiro o nomeou para a Secretaria da Educação de Minas Gerais, na qual tomou posse em 14 de abril de 1967. "Valendo-se de suas boas relações nos altos escalões federais, resolvia os problemas financeiros enfrentados pela secretaria (Badaró, 1996, p. 347).

Apesar de Alkmin ter sido vice-presidente da República e de pertencer à Arena, não esteve livre de perseguições políticas. Com a morte do ex-presidente Costa e Silva, o general Orlando Geisel foi nomeado chefe do Estado-Maior do Exército e começaram a surgir as listas de cassações, estando o nome de José Maria Alkmin incluído. Por esse motivo, Israel Pinheiro decidiu exonerá-lo da Secretaria da Educação. Este fez uma longa peregrinação de conversas com civis e militares, até conseguir salvar seu mandato e manter-se como deputado federal.

Em 1970, Alkmin, após uma longa e vitoriosa carreira, não conseguiu votos suficientes para se reeleger, ficando na primeira suplência da Arena. Sua derrota causou-lhe profunda decepção e mágoas. "Seu refúgio era a Santa Casa, onde entregou-se ao trabalho da provedoria com ânimo redobrado” (Badaró, 1996, p. 359). Um acidente automobilístico, porém, vitimou o deputado Edgar Pereira, no dia 11 de abril de 1973. O então presidente da Câmara dos Deputados, Flávio Marcílio, telefonou para Alkmin, convocando-o para assumir a cadeira vaga, já que ele era o primeiro suplente. No dia 13 de junho de 1973, Alkmin reassumiu sua cadeira na Câmara dos Deputados pela última vez.

Após longa carreira política, com atuação destacada como vice-presidente da República e na Câmara dos Deputados, além de ter exercido diversos cargos executivos tanto na iniciativa privada e, sobretudo, no poder público, Alkmin adoeceu e foi hospitalizado, em março de 1974. Faleceu em Belo Horizonte, em 22 de abril de 1974, aos 72 anos de idade.

\section{As ideias econômicas de José Maria Alkmin}

O pensamento econômico de José Maria Alkmin pode ser classificado como liberal e conservador, tanto pela sua atuação nos postos de comando por onde passou como pelas agremiações políticas pelas quais se elegeu e exerceu seus mandatos. Foi um político tradicional mineiro, exímio articulador, mais conhecido por suas defesas de causas diante dos demais deputados, na Câmara Federal, do que propriamente por suas ideias econômicas.

Ao descreverem o período final do varguismo, após o término da Segunda Guerra 
Mundial, Schwarcz e Starling (2015) mencionam o fato de Vargas ter criado dois partidos. O PSD - do qual Alkmin foi um dos fundadores em Minas Gerais, em parceria com JK, agremiação que se utilizou da estrutura partidária visando às benesses da máquina administrativa estadual e operou sua capacidade de se ramificar pelo interior do estado até atingir o eleitorado dos municípios. O segundo, o Partido Trabalhista Brasileiro (PTB), "não foi concebido para ser um partido dos trabalhadores, mas era, sem dúvida, um partido criado para os trabalhadores (Scwarcz; Starling, 2015, p. 393). As autoras destacam outra característica de Alkmin ao afirmar que "os grandes pessedistas eram mestres na capacidade de confabular e conchavar: Tancredo Neves, Juscelino Kubitscheck, Amaral Peixoto, José Maria Alkmin, Ulysses Guimarães” (Scwarcz; Starling, 2015, p. 393). Observa-se, portanto, que Alkmin ao lado de nomes facilmente identificáveis na tradicional política brasileira.

Um segundo aspecto que, de certa forma, elucida os meandros de suas ideias econômicas foi sua dedicação aos pobres via trabalho na Santa Casa de Misericórdia em Belo Horizonte. A esta atividade, Alkmin dedicou toda sua vida, mesmo nos momentos de maior intensidade de atuação política. Quando deixou o Ministério da Fazenda, sua preocupação imediata era cuidar melhor da Santa Casa. "Mesmo quando ministro, jamais deixou de estar presente às reuniões da mesa administrativa, tomando providências, convocando amigos endinheirados para não deixarem faltar o mínimo para os doentes e internados. Essa atividade, de um ministro de Estado pelos imensos corredores do hospital e suas dependências, causava assombro e admiração" (Badaró, 1996, p. 273).

José Maria também dedicou boa parcela de seu tempo atuando nas penitenciárias mineiras, introduzindo, inclusive, uma série de inovações no sentido de "recuperar" os detentos via trabalho e aprendizado de nova profissão que lhes permitisse sustento financeiro ao deixar o sistema prisional. No entanto, nem num caso nem no outro, percebe-se um "sentido econômico" de suas ações com vistas a promover, de fato, uma distribuição efetiva de renda ou uma mudança nas estruturas econômico-sociais brasileiras. Seu foco, tanto nos discursos como nas ações, sequer mencionava ou defendia a reforma agrária, que seria uma maneira de melhorar a vida dos $80 \%$ dos detentos oriundos do meio rural.

Diante de sua formação jurídica e de sua atuação política, são as ações nos vários cargos ocupados por Alkmin no decorrer de sua vida que melhor aferem o que ele, de fato, pensava a respeito de questões econômicas. No discurso de posse como Secretário de Finanças no governo mineiro, em $1^{\text {o }}$ de fevereiro de 1951, por exemplo, prometeu esforço no sentido de tirar Minas da grave crise econômico-financeira, mesmo que os resultados não fossem imediatos. Afirmou que seria "um erro esperar que os problemas se solucionem rapidamente. Há, porém, um único caminho, a vida do trabalho em que nos empenharemos todos sob a liderança do governador Juscelino Kubitschek" (Alkmin, 1951). No final do primeiro mês de mandato na secretaria, reuniu a imprensa para sua primeira entrevista coletiva, na qual detalhou a situação das finanças estaduais. Descreveu o programa de recuperação fiscal, dando realce ao combate à sonegação, eliminação do déficit e à contenção das despesas públicas.

Alkmin dedicou, desde a chegada à Secretaria de Finanças, um esforço no sentido de aprofundar seus conhecimentos em economia. De um lado, atuou como professor nas disciplinas de Economia Política e História das Doutrinas Econômicas, na Faculdade de

4 José Maria Alkmin. Discurso de posse como Secretário das Finanças. Belo Horizonte, 1º de fevereiro de 1951. 
Filosofia da Universidade de Minas Gerais. Obviamente que o preparo das aulas, assim como o efetivo exercício de professor o levaram a ler os clássicos, como também a entender as diferentes conjunturas econômicas ao longo do tempo. Este aprendizado foi depois levado para a atuação nos diferentes cargos executivos que exerceu ao longo da carreira.

Ao deixar a secretaria, assumiu, em 20 de outubro de 1953, a Carteira de Redescontos e Caixa de Mobilização Bancária do Banco do Brasil. "Depois da posse na Carteira de Redescontos do Banco do Brasil, Alkmin procurou aperfeiçoar-se ao máximo, estudando detidamente a questão cambial, mergulhando profundamente no exame do intricado mercado financeiro e suas ligações internacionais, mais tarde de grande utilidade quando no cargo do Ministério da Fazenda" (Badaró, 1996, p. 194). Tal passagem de seu biógrafo mostra o interesse que Alkmin tinha em aprofundar seus conhecimentos econômico-financeiros a fim de se apossar de ferramental necessário para a boa atuação nos cargos que ocupou.

\section{O governo JK e a atuação de José Maria Alkmin no Ministério dA FAZENDA (1956-1958)}

Após 25 anos de transformações na estrutura do Estado e de desenvolvimento da indústria e de construção dos pré-requisitos de infraestrutura sob a égide do Estado, apresentou-se um modo de articular a entrada da empresa estrangeira a uma dinâmica industrial de perfil avançado (DRAIBE, 1985).

Eleito em outubro de 1955 pelo PSD, Juscelino Kubitschek já em sua campanha eleitoral sublinhava o momento transitório em que o país se encontrava, de um passado essencialmente agrário para um futuro industrial e urbano e defendia a aceleração da industrialização como o meio mais eficiente para enfrentar os problemas de um país populoso e abundante em recursos naturais (VILLELA, 2011). Juscelino foi eleito em um contexto de transformação da economia internacional em que ocorre a retomada do processo de internacionalização do capital calcado na expansão de multinacionais para a periferia, principalmente de empresas norte-americanas e europeias em busca de mercados, matéria-prima, mão de obra barata e facilidades fiscais (CORSI, 2010).

Em consonância com esse processo, o governo adotou uma política de desenvolvimento baseada na associação com capitais externos, visível no crescimento do Investimento Externo Direto (IED) que de 1951-1955 era de 340 milhões de dólares e passa a 700 milhões de dólares em 1956-1960, e no aumento da dívida externa líquida, a qual se expande de menos de 1 bilhão para 3,4 bilhões de dólares no período entre 1955 a 1960 (VILLELA, 2011). Utilizou a Instrução 113 da SUMOC, implantada no Governo Café Filho, para sua estratégia e durante o governo cerca de 380 milhões de dólares entraram no país para as indústrias de base e outros 130 milhões para as indústrias leves através dessa medida (CORSI, 2010). Ademais, a existência de uma demanda reprimida por bens de consumo duráveis decorrente da concentração de renda também constituiu elemento importante para introdução do projeto de desenvolvimento associado.

O governo JK caracterizou-se por um intenso comprometimento do setor público com uma explícita política de desenvolvimento. Para isso, o Estado definiu um conjunto de investimentos e "assegurou as condições mínimas de financiamento, estendendo ao limite seu 
poder de regulação e a capacidade fiscal e financeira" (DRAIBE, 1985). Em outubro de 1956, é anunciado o Plano de Metas, marco do governo JK, como resposta aos estrangulamentos setoriais da economia e com o objetivo de aprofundar a industrialização brasileira de tal forma que garantisse a reprodução ampliada do capital. Para Tavares (1986), "o novo perfil de investimento que se desenha e a diferenciação industrial que se pretende requerem investimentos maciços, tanto estatais quanto estrangeiros”. Dessa forma, o plano previa 355 bilhões de cruzeiros de investimentos nas áreas de energia, transporte, siderurgia, indústria de base, alimentação e educação, com foco nos primeiros quatro (CORSI, 2010).

As inversões sociais, entretanto, além das metas de armazenamento e comercialização de produtos agropecuários tiveram pequeno peso nos objetivos do Plano. Centralmente, visava-se à construção de grandes hidrelétricas, de indústrias de refino de petróleo, além da modernização do sistema ferroviário e a expansão dos setores siderúrgico e de cimento, áreas em que o empresariado nacional não tinha interesse. Além desses setores, a transferência da capital nacional com a construção de Brasília significou a ampliação do espaço econômico brasileiro. Consolida-se o movimento, inaugurado no início da década, pelo qual o setor privado consciente da vulnerabilidade da economia delega ao Estado a tarefa de complementação industrial (LESSA, 1982).

Foi nesse quadro mais amplo que José Maria Alkmin assumiu o Ministério da Fazenda em $1^{\circ}$ de fevereiro de 1956. Em seu discurso de posse, Alkmin descreveu as linhas básicas de seu pensamento sobre os temas mais relevantes da economia nacional e a orientação recebida do novo presidente para envidar esforços no sentido de incorporar a iniciativa privada ao anunciado Programa (ou Plano, como ficou popularmente conhecido) de Metas. Na ocasião, defendeu a participação da iniciativa privada como fator de estímulo ao crescimento econômico, sem descartar uma "intervenção supletiva para garanti-lo", reconhecendo, logo em seguida, a situação por que passava a economia brasileira: crise cambial, monetária e de abastecimento. Além do plano de investimentos, a construção de Brasília, a famosa metasíntese, também constava na agenda do novo ministro da Fazenda.

Couto $(2001,2011,2013)$ destaca a participação de Alkmin no Plano de Metas, audacioso projeto de desenvolvimento que compreendia 30 metas setoriais e a construção da nova capital federal, erguida em 42 meses no sertão de Goiás. O governo ${ }^{5}$ realizou investimentos maciços em energia, transportes, indústrias de base, alimentação e educação. Promoveu a integração nacional, a ocupação e o crescimento do interior. Implantou a indústria automotiva, fez grandes hidrelétricas e mais de 20 mil quilômetros de rodovias. No quinquênio 1956-1961, a economia brasileira cresceu quase 50\%. Ademais, promoveu-se intenso florescimento das artes: era o Cinema Novo, a poesia concreta, a Bossa Nova, a literatura, o teatro, as artes plásticas, a arquitetura modernista.

Sabe-se que, no momento de sua posse no Ministério da Fazenda, o café ainda era o principal produto da balança comercial brasileira. A ele dedicou especial atenção, em seu discurso, estabelecendo regras capazes de tranquilizar um mercado muito sensível e sujeito

\footnotetext{
5 Juscelino Kubitschek teve uma vida marcante no cenário político, tanto a nível estadual como nacional. Como prefeito, implementou mudanças marcantes na capital mineira, como a construção da Pampulha; como presidente, a construção de Brasília. Para maiores detalhes sobre sua vida e obra, ver os textos de Ronaldo Costa Couto: O essencial de JK: sonho e grandeza, amor e tristeza. São Paulo: Planeta do Brasil, 2013; Juscelino Kubitscheck. Brasília: Câmara dos Deputados-Senado Federal, 2011; Brasília Kubitschek de Oliveira. Rio de Janeiro: Record, 2001.
} 
à ação dos especuladores. "A política do café deve orientar-se no sentido de erradicar a desconfiança e diminuir a instabilidade de preço, prejudicial tanto a exportadores quanto a importadores. Considero fundamental um entendimento entre os países produtores e o principal consumidor - os Estados Unidos - pela via de um acordo que vise não à valorização artificial do produto, mas à estabilização de seus preços num nível capaz de estimular o consumo, sem ao mesmo tempo, provocar um colapso econômico nos países produtores” (Alkmin, 1956).

Outro tema que mereceu especial atenção no mesmo discurso foi a a alta dos preços. "O combate à inflação não é tarefa fácil nem politicamente agradável. Mas é indispensável e urgente", proclamou o ministro. Falou, ainda, do saneamento da moeda, "tarefa a ser enfrentada, não apenas pela compressão das despesas, mas também por um esforço decidido da melhoria da arrecadação”. Repetiu o sumo da filosofia implantada em sua administração quando secretário das Finanças de Minas Gerais: "Tributar com justiça e arrecadar com severidade é uma norma de um governo prudente" (Alkmin, 1956).

Abordou, ainda, o problema da expansão do crédito bancário, "que deve ser contida em limites razoáveis, evitando-se o que já sucedeu em outras fases da vida brasileira, em que o Ministério da Fazenda se esforçava para comprimir gastos, ao passo que o sistema bancário expandia demasiadamente o crédito, impossibilitando uma luta coordenada contra a inflação”. Deixou claro, por fim, "que estes cuidados não significariam restrições ao crédito e à produção, a ser disseminado à grande massa superior a dois milhões de produtores espalhados pelo país. Esse conjunto de providências nada mais é do que a estruturação e o alicerce indispensáveis ao lançamento do Banco Rural, um dos objetivos do governo”.

Ao assumir a pasta, Alkmin herdou a difícil situação econômico-financeira dos governos de Getúlio Vargas e Café Filho ${ }^{6}$. A superprodução do café, os déficits do Tesouro e a perda do poder de compra das exportações formavam na época, segundo Lessa (1983), um "quadro impressionante de desequilíbrios econômicos”. Entretanto, em vez de formular uma política de estabilização financeira, tal como o fizeram Eugênio Gudin e José Maria Whitaker, titulares da pasta da Fazenda no governo Café Filho, Alkmin propôs-se basicamente a impedir que os desequilíbrios tomassem vulto a ponto de comprometer o êxito do programa desenvolvimentista de Kubitschek.

Alkmin iniciou a gestão no ministério sob expectativas de mudança do regime cambial. Em setembro de 1955, o então ministro da Fazenda, José Maria Whitaker, apresentou um plano elaborado em conjunto com Edward Bernstein, representante do Fundo Monetário Internacional (FMI) no Brasil. O plano pretendia estabelecer o regime de câmbio livre em substituição ao sistema múltiplo de câmbio instituído em 1953 no governo Vargas. Suas principais consequências seriam a desvalorização do cruzeiro e a supressão do "confisco cambial”, mecanismo que propiciava ao governo recursos adicionais para comprar os excedentes de produção do café e subsidiar as importações de petróleo, trigo, papel e outros produtos básicos.

O novo ministro se opôs à reforma cambial e a abandonar a política de defesa do café, entrando em divergência com Lucas Lopes, presidente do Banco Nacional de Desenvolvimento

6 Este parágrafo e os próximos estão baseados na biografia de José Maria Alkmin, de Paulo Brandi, disponível em: http:// www.fgv.br/cpdoc/acervo/dicionarios/verbete-biografico/alkmin-jose-maria. Acesso em: 07 Mar. 2019. 
Econômico (BNDE) e Roberto Campos, diretor-superintendente da mesma entidade. Apoiando o ministro da Fazenda, JK rejeitou a reforma em março de 1956, permitindo que a política cambial contribuísse como um dos instrumentos básicos da nova política de desenvolvimento industrial do Plano de Metas.

Por meio da Instrução no 127 da Superintendência da Moeda e do Crédito (SUMOC), de 1956, os equipamentos destinados a setores básicos da economia, como os da produção de veículos e da indústria naval, passaram a figurar, junto com o petróleo, papel e trigo, entre os produtos de importação fortemente subsidiados. Em relação aos cafeicultores, Alkmin manteve o confisco cambial, de um lado, para garantir as bonificações pagas aos exportadores. Por outro lado, no entanto, beneficiou-os ao assegurar a compra de toda produção cafeeira nacional.

Nesse sentido, a política monetária do Ministério da Fazenda procurou atender, ao mesmo tempo, dois objetivos: (1) assegurar o crédito necessário à expansão dos investimentos públicos, um dos pilares do Plano de Metas; (2) atenuar a inflação, que era um dos temas candentes na economia dos anos 1950. Neste caso, o principal instrumento de combate à inflação foi a Instrução no 135 SUMOC, editada em 19 de julho de 1956, e pela qual se restringia o crédito bancário ao setor privado.

No final do primeiro ano de gestão, dois fatos mostravam-se claros: o limitado alcance das medidas anti-inflacionárias e o êxito da política de valorização do café. Pela análise de Peláez e Suzigan $(1976,1978)$ o aumento da inflação causou uma queda na taxa de crescimento da renda real, provocada pelo fraco desempenho do setor agrícola. Em compensação, houve recuperação da produção industrial, que aumentava na medida em que se implantava o Plano de Metas.

Pelo lado da arrecadação, Alkmin sancionou, em agosto de 1957, a Lei das Tarifas, após aprovação no Congresso. Por ela, instituíram-se alíquotas protecionistas ad valorem, reduzindo as cinco categorias anteriormente existentes para duas. Esta lei ergueu poderosa proteção aos produtores nacionais, contribuindo para a oligopolização dos novos setores industriais. Por outro lado, representou importante aproximação no sentido de uniformizar as taxas diferenciais de câmbio, medida reclamada havia tempo pelo FMI.

$\mathrm{Na}$ arena internacional, Alkmin desempenhou um papel coadjuvante. No começo de outubro de 1957, o ministro foi à reunião anual da Junta de Governadores do FMI e do Banco Mundial em Washington, ocasião na qual negociou empréstimos no valor de US\$ 59 milhões, adiantados pelo FMI e bancos privados norte-americanos para aliviar as pressões sobre o balanço de pagamentos.

Ainda em 1957, Alkmin propôs reatar as relações comerciais com a União Soviética, com vistas, sobretudo, à diversificação dos parceiros comerciais do Brasil. O ministro da Guerra, general Henrique Lott, no entanto, foi radicalmente contrário, e, num gesto de cálculo político, passou a responsabilizar o ministro da Fazenda pela crise financeira. Alkmin, viu-se na posição incômoda de ser apoiado pelos líderes da esquerda, como o secretáriogeral do Partido Comunista Brasileiro, Luís Carlos Prestes, que, em março de 1958, elogiou publicamente sua política econômica ao propor a formação de uma frente democrática e nacionalista. Apesar dos esforços do ministério, o ano de 1957 terminou com um expressivo déficit de US\$ 286 milhões no balanço de pagamentos. Tal situação foi provocada pela situação 
desfavorável do café e pelo aumento das importações de máquinas e equipamentos visando a atender a demanda das novas indústrias.

No decorrer de 1958, Alkmin tentou obter novos financiamentos internacionais, solicitando ao Eximbank e a bancos privados dos Estados Unidos, empréstimos com pagamento a prazo exíguo, do tipo swap, no valor de US\$ 200 milhões, além da liberação de nova quota de US\$ 37,5 milhões junto ao FMI. O Fundo, entretanto, condicionou a ajuda à execução de uma série de medidas que a seu ver regularizariam a situação financeira do Brasil. Após prolongadas negociações, Alkmin obteve o empréstimo solicitado mediante o compromisso de realizar as reformas exigidas pelo FMI. Todavia, as restrições feitas pelo organismo internacional criaram sérios obstáculos à aprovação norte-americana do empréstimo de US\$ 200 milhões. Os embaraços impostos pelos grandes bancos internacionais e o aumento da inflação no primeiro semestre de 1958 expuseram o então ministro da Fazenda a críticas generalizadas, contribuindo para seu desgaste e, consequentemente, para sua futura queda.

Um dos principais desafios enfrentados por Alkmin durante sua passagem pela Fazenda deu-se nas questões relacionadas ao café. Já no início de 1957, surgiram os primeiros sinais de crise nos preços do café durante sua gestão. Alkmin decidiu reter parte da receita da exportação do produto para utilizá-la na compra dos excedentes. Os cafeicultores de São Paulo, Minas Gerais e Paraná organizaram um protesto e prepararam uma marcha rumo ao Palácio do Catete, no Rio de Janeiro, no dia 18 de junho de 1957. Devido a disputas internas, porém, a caravana não chegou a se concretizar. Este fato fez com que os cafeicultores passassem a reivindicar a saída de Alkmin do Ministério da Fazenda. O movimento de defesa do café retomou suas atividades no ano seguinte, tendo a marcha novamente frustrada, porém, pela atuação do Exército.

Diante da crise supracitada, os cafeicultores passaram a reivindicar uma reforma cambial. Apoiado nos pareceres dos técnicos do Instituto Brasileiro do Café, Alkmin decidiu rejeitá-la, argumentando que a safra de 1956 já havia sido uma das menores até então; por isso, a conjuntura não poderia ser tomada como parâmetro para adoção de política pública de defesa do setor ${ }^{7}$. Naquele ano, foram colhidas apenas 12 milhões de sacas e, por isso, não havia qualquer razão para alterar uma política cambial diferenciada em relação ao setor cafeeiro. Ademais, o preço do produto no mercado externo estava em níveis satisfatórios, e, devido ao acúmulo de estoques, havia tranquilidade no comércio internacional. "Vendemos, ao final de 1956, cerca de 16 milhões e 800 mil sacas de café, pelo preço médio de US\$ 61, permitindo uma receita recorde de US\$ 1,29 bilhão" (Badaró, 1996, p. 266). Como toda produção agrícola, atividade inerentemente de alto risco, o café sofreu, no final de 1956 e início do ano seguinte, os efeitos de severa estiagem, provocando a já citada redução da safra seguinte.

Diante das dificuldades que enfrentava o principal produto da pauta de exportações brasileira, o governo brasileiro enviou Paulo Guzzo, presidente do Instituto Brasileiro do Café, para uma missão no México em que foi formalizado o Convênio do México, pelo qual seis países da América Latina estabeleceram, pela primeira vez, um regime de quotas de exportação do produto. Em janeiro de 1957, Alkmin promoveu, no Rio de Janeiro, a

7 Ao invés de aprovar a demanda dos cafeicultores, o ministro, com a ajuda de Assis Chateaubriand, impulsionador da atividade cafeeira, iniciou uma grande campanha em favor da produção de cafés finos, com o objetivo de conquistar novos consumidores, especialmente na Europa, cada vez mais exigentes quanto à qualidade do produto. 
Conferência Internacional do Café. Neste evento, o Convênio do México foi apoiado por 14 países produtores latino-americanos e Portugal, que ainda respondia por suas colonias. $\mathrm{O}$ Brasil propôs que países produtores e consumidores se unissem para estabilizar os preços do café, incumbindo, para tanto, a recém-criada Organização Internacional do Café (OIC). No entanto, a oposição de Estados Unidos e Bélgica inviabilizou sua operação, e ela só passou a funcionar a partir de 1963, após longas negociações na ONU.

Dada a centralidade do Ministério da Fazenda, lá desembocavam os principais problemas da administração federal. A primeira dificuldade enfrentada por Alkmin no cargo fora logo no início do mandato, em 7 de fevereiro de 1956, quando Kubitschek decidiu nomear Tancredo Neves para a Carteira de Redescontos do Banco do Brasil, cargo ocupado anteriormente por ele. "Foi como tomar óleo de rícino com o dedo no nariz", relatou a amigos. Esta desconfiança se manifestou na prática, quando, em 1957, Alkmin fez sua primeira viagem aos Estados Unidos para participar da reunião do board do Fundo Monetário Internacional e do Banco Mundial. Para seu lugar foi designado interinamente Sebastião Paes de Almeida. Tancredo Neves, diretor da Carteira de Redescontos, foi alçado temporariamente à presidência do Banco do Brasil. "Em sua volta, Alkmin constatou os estragos feitos pela curta passagem de Tancredo pela presidência do Banco do Brasil, como a realização de empréstimos altamente inflacionários e de conteúdo duvidoso. Foi mais um ponto de fricção entre ambos, em suas já difíceis relações” (Badaró, 1996, p. 255). Em consequência, Alkmin decidiu que não deixaria mais Tancredo assumir a presidência do Banco do Brasil durante seu mandato.

O ministro também percebeu que outro problema de difícil solução política seria promover um ajuste fiscal socialmente justo. Logo no início da gestão, já havia "declarado guerra" aos sonegadores, determinando providências para a cobrança da dívida ativa. Para tanto, traçou algumas normas e fixou critérios para atingir tais objetivos. Primeiro tratou de impedir que os cargos de delegados do Imposto de Renda, superintendentes da Receita nos estados e inspetores da alfândega no Rio de Janeiro e em Santos fossem providos por critérios políticos ou por indicações de parlamentares. Outro flanco de luta foi aberto nas alfândegas, locais por onde se dava a evasão de divisas brasileiras. Enfrentou interesses arraigados para impedir a reiterada liberalidade da Justiça na concessão de mandados de segurança, precedidos de medidas liminares para liberação dos bens apreendidos.

Tais medidas econômico-financeiras trouxaram-lhe adversidades políticas. Autoridades públicas tiveram o dissabor de ver malas e objetos de viagem retidos no desembaraço alfandegário. "Não cedia sob nenhum pretexto. Chocante era a constrangedora visão de milhares de automóveis importados ilegalmente estacionados na esplanada do Castelo. Carros de luxo vindos dos Estados Unidos e da Europa, em flagrante desrespeito às leis brasileiras. A ordem era uma só: apreender tudo" (Badaró, 1996, p. 246). Para combater o crédito especulativo, lançou a Instrução no 135 da SUMOC, não sem antes vencer sérias resistências pela reação de uma minoria alimentada e acostumada a viver do crédito fácil e da especulação.

Alkmin também promoveu reformas na economia. Sobre o sistema cambial brasileiro, afirmava que algumas de suas características "não poderiam ser considerados como contribuição ao nosso esforço de desenvolvimento econômico e nos mortificava constatar que o preço da moeda estrangeira para importação de um equipamento indispensável à nossa produção era duas vezes mais caro que se essa moeda fosse despendida em viagens 
ao exterior" (Alkmin, 1958). Nesse sentido, demonstrava contrariedade ao "verificar que os nossos exportadores eram punidos ao tentarem colocar seus produtos nos mercados externos, quer pelo desestímulo advindo de nossas exigências burocráticas, quer como decorrência de taxas cambiais muito aquém da realidade” (Alkmin, 1958).

Um último ponto de atrito entre o ministro e vários setores políticos foi a construção de Brasília. Alkmin concordava com a importância simbólica da obra, mas a pressa e o volume de gastos em meio a uma política de rigorosa contenção inflacionária, o incomodava. Israel Pinheiro, presidente da Novacap ${ }^{8}$, tocava as obras no passo que se convencionou denominar de "ritmo de Brasília", movimentando o ministério em busca da liberação de recursos. Por fim, entre os vetores que contribuíram para o desgaste do ministro encontrava-se o desejo de Tancredo Neves de afastá-lo do cargo, livrando-se de um possível concorrente ao governo de Minas nas eleições de 1960.

Diante das pressões supracitadas, aliadas aos interesses de Juscelino de atender a demanda de novos grupos políticos, Alkmin veio a exonerar-se do posto de ministro de Estado da Fazenda no dia 24 de junho de 1958, sendo substituído por Lucas Lopes.

\section{CONSIDERAÇÕES FINAIS}

José Maria Alkmin foi ministro da Fazenda num período chave da política e da economia do país. O período em que esteve à frente da economia do país foi marcado por, pelo menos, três fatos marcantes. O primeiro diz respeito à passagem de uma economia agrícola para a industrial. De acordo com Fausto (2001, p. 299), "no curso dos anos 1950-1980 o Brasil se tornou um país semi-industrializado, com o produto industrial mais elevado de todos os países do chamado Terceiro Mundo". Foi o momento histórico mais intenso do famoso "processo de industrialização através da substituição de importações”. O Plano de Metas do governo JK, um dos mais bem elaborados e executados na história econômica brasileira, contribuiu na passagem do país de uma economia essencialmente agrário-exportadora para uma economia industrial.

O segundo ponto de destaque na atuação de Alkmin no Ministério da Fazenda foi garantir os recursos necessários para a construção de Brasília. Tal projeto foi motivo de muitas críticas, das dificuldades logísticas aos altos custos de realização; por outro lado, significou a realização de um sonho de políticos e economistas que já dominavam os debates, pelo menos, desde o início da implantação da República, no final do século XIX. Brasília constituiuse, além disso, numa cidade inovadora que, mais tarde, tornou-se patrimônio histórico da humanidade, apesar de ser uma cópia do que existe de perverso nas demais grandes cidades: a expulsão da classe trabalhadora para as longínquas, pobres e periféricas áreas urbanas.

Um terceiro destaque, como consequência deste último, foi a continuação de um movimento de ocupação do Centro-Oeste e do Norte do país, iniciado com a busca pelo ouro, a caça de índios, a procura pelo látex da borracha etc. Desde o descobrimento até

8 Companhia Urbanizadora da Nova Capital (Novacap), empresa pública vinculada à Secretaria de Viação e Obras do Distrito Federal (Brasília), foi criada em 19 de setembro de 1956 pela Lei no 2.874, com a finalidade de executar os serviços de urbanização e de construção da nova capital da República. O engenheiro Israel Pinheiro foi indicado como presidente da companhia e o arquiteto Oscar Niemeyer como diretor técnico. Tão logo assumiu, Niemeyer começou a elaborar projetos para os primeiros edifícios e organizou um concurso para a criação do projeto urbanístico do núcleo da cidade, o chamado Plano Piloto, cujo vencedor foi o urbanista Lúcio Costa. 
meados do século XX, cerca de $90 \%$ da população brasileira localizava-se no litoral ou em suas proximidades. Como consequência, as atividades econômicas também se concentravam nessas regiões. A construção de Brasília, acompanhada da abertura de estradas em direção ao Norte, Nordeste e extremo Oeste permitiram uma nova ocupação demográfica e o deslocamento de parte da produção agrícola-agropecuária para essas áreas. Em partes também a produção industrial e o setor de serviços acompanharam tal mudança demográfica.

Em relação à postura de José Maria Alkmin, merece destaque seu pronunciamento no discurso de posse da Câmara dos Deputados de 5 de dezembro de 1958, em resposta a seus críticos de que teria utilizado seus cargos na Secretaria de Finanças de Minas e no Ministério da Fazenda para enriquecimento próprio. $\mathrm{Na}$ ocasião, ele explanou suas ações realizadas como ministro de Estado e explicitou sua situação financeira pessoal, dizendo que vendeu a única casa que havia construído em 1932. Como os recursos auferidos não foram suficientes para construir outra, havia contraído empréstimo junto ao Instituto dos Bancários. "Não só a Secretaria das Finanças, em Minas Gerais, como o Ministério da Fazenda, no Rio, só me serviram para maiores privações, para mim e para minha família" (apud Couto, 1996, p. 274).

Ainda assim, argumenta-se neste artigo que se tratou de um homem de sua época. Liberal em termos econômicos, conservadores em matérias políticas, José Maria Alkmin cerrou fileiras com os lideres do golpe civil-militar de 1964. Conquanto demonstrasse real preocupação com setores menos favorecidos da sociedade brasileira, jamais postou-se a favor de transformações, sequer pontuais, na estrutura de renda e patrimônio de um dos países mais desiguais do mundo.

Sem incorrer em debate anacrônico acerca de suas posições político-econômicas, entende-se a atuação política de Alkmin como a de um típico representante da elite mineira da primeira metade do século XX. Ainda assim, não se pode negligenciar sua atuante participação no cenário político de seu estado e, de modo mais especifico, sua passagem pelo Ministério da Fazenda em momento nevrálgico do desenvolvimento econômico brasileiro. 


\section{REFERÊNCIAS BIBLIOGRÁFICAS}

ALKMIN, José Maria. Discurso na Assembleia Nacional Constituinte. Rio de Janeiro, 26 de março de 1934.

ALKMIN, José Maria. Discurso de posse na Secretaria do Interior do Estado de Minas Gerais. Belo Horizonte, 19 de setembro de 1936.

ALKMIN, José Maria. Discurso proferido no lançamento da campanha de Eurico Gaspar Dutra à presidência da República. Belo Horizonte, 8 de abril de 1945.

ALKMIN, José Maria. Discurso na Assembleia Nacional Constituinte. Rio de Janeiro, 18 de junho de 1946.

ALKMIN, José Maria. Discurso de posse como Secretário das Finanças. Belo Horizonte, $1^{\circ}$ de fevereiro de 1951.

ALKMIN, José Maria. Discurso de despedida da Secretaria das Finanças. Belo Horizonte, 19 de outubro de 1953.

ALKMIN, José Maria. Discurso na Câmara dos Deputados. Rio de Janeiro, 13 de abril de 1955.

ALKMIN, José Maria. Discurso de posse como Ministro da Fazenda. Rio de Janeiro, $1^{\circ}$ de fevereiro de 1956.

ALKMIN, José Maria. Discurso de posse na Câmara dos Deputados. Rio de Janeiro, 5 de dezembro de 1958.

ALKMIN, José Maria. Discurso de posse na Câmara dos Deputados. Brasília, 13 de junho de 1973.

BADARÓ, Murilo. José Maria Alkmin. Uma biografia. Rio de Janeiro: Nova Fronteira, 1996.

BRANDI, Paulo. José Maria Alkmin. Disponível em: http://www.fgv.br/cpdoc/acervo/ dicionarios/verbete-biografico/alkmin-jose-maria. Acesso em: 07 Mar. 2019.

CORSI, Francisco L. A criação das bases da industrialização (1930-1945). In: PIRES, M. C.

Economia Brasileira: da colônia ao governo Lula. São Paulo: Saraiva, 2010.

COUTO, Ronaldo C. Brasília Kubitschek de Oliveira. Rio de Janeiro: Record, 2001.

COUTO, Ronaldo C. Juscelino Kubitscheck. Brasília: Câmara dos Deputados-Senado Federal, 2011.

COUTO, Ronaldo C. O essencial de JK: sonho e grandeza, amor e tristeza. São Paulo: Planeta do Brasil, 2013.

COUTO, Ronaldo C. A saga da família Klabin-Lafer. Rio de Janeiro: Chermont Editora, 2017.

DRAIBE, Sonia. M. Rumos e Metamorfoses: Estado e Industrialização no Brasil. São Paulo: Paz e Terra, 1986.

FAUSTO, Boris. História concisa do Brasil. São Paulo: Imprensa Oficial do Estado, 2001.

FONSECA, Pedro Cezar D. Estado e industrialização consciente: 1930-45. Questões de Economia Política. Porto Alegre, n. 4. 1987.

FONSECA, Pedro Cezar D. O processo de substituição de importações. In REGO, J. M.; MARQUES, R. M. (Orgs.). Formação Econômica do Brasil. São Paulo: Saraiva, 2003. 
LESSA, Carlos Francisco Theodoro M. R. de. Quinze anos de política econômica. 4.ed. São Paulo: Brasiliense, 1983.

OLIVEIRA, Ricardo C. de. O silêncio dos vencedores. Genealogia, classe dominante e Estado no Paraná. Curitiba: Moinho do Verbo, 2001.

OLIVEIRA, Ricardo C. Família importa e explica: Instituições políticas e parentesco no Brasil. São Paulo: LiberArs, 2018.

PELÁEZ, Carlos Manuel; SUZIGAN, Wilson. História monetária do Brasil: Análise da política, comportamento e instituições monetárias. Rio de Janeiro: IPEA, 1976.

PELÁEZ, Carlos Manuel; SUZIGAN, Wilson. Economia Monetária: Taeoria, política e evidência empírica. São Paulo: Atlas, 1978.

SCHWARCZ, Lilia M.; STARLING, Helena M. Brasil: uma biografia. São Paulo: Companhia das Letras, 2015.

SZMRECSÁNYI, Tamás. Apontamentos para uma História do Brasil no Período 1920-50.

Ensaios FEE, Porto Alegre, n.7,1986.

TAVARES, Maria da Conceição. Acumulação de Capital e Industrialização no Brasil. Campinas: UNICAMP, 1986.

VILLELA, André A. Dos “Anos Dourados” de JK à Crise não Resolvida. In: GIAMBIAGI, Fabio et al. (Orgs.). Economia Brasileira Contemporânea. Rio de Janeiro: Elsevier, 2011. 